\title{
A “ideologia de gênero" na discussão do PNE: a intervenção da hierarquia católica
}

\author{
The "gender ideology" in the PNE discussion: \\ the intervention of the Catholic hierarchy
}

Maria José Fontelas Rosado-Nunes*

\begin{abstract}
Resumo
O presente artigo trata das manifestações públicas de agentes religiosos católicos, membros da hierarquia e leigos reconhecidos por ela, no contexto da discussão do Plano Nacional de Educação PNE. O foco da análise é a condenação do que denominam "a ideologia de gênero", presente na proposta do documento. Tais manifestações constituem a reafirmação de uma concepção dos seres humanos como submetidos às inexoráveis "leis da natureza" que determinam uma ordem social pautada pela rígida distinção das funções atribuídas às mulheres e aos homens. Os textos publicados à época revelam mudanças e permanências no discurso católico em sua referência à "natureza", compreendida em sua materialidade biológica, como um dado inarredável da realidade humana, constituída em dois sexos que devem unir-se segundo a "ordem natural". As teorias de gênero são responsabilizadas pela desestruturação da família, por oferecerem suporte a novas compreensões da humanidade, já não assente sobre a bipolaridade: homens / mulheres. Um dossiê não extensivo desses textos constituiu a base para as análises propostas.
\end{abstract}

Palavras-chave: ideologia de gênero; conservadorismo religioso; Catolicismo; Plano Nacional de Educação; ordem natural

\begin{abstract}
This article deals with public manifestations of Catholic religious officials, members of the hierarchy and recognized laity, in the context of the discussion of the National Education Plan - PNE. The focus of the analysis is a condemnation of what they call "gender ideology", present in the proposal document. Such manifestations are the reaffirmation of a conception of human beings as subject to the inexorable "laws of nature" that determine a social order marked by the rigid distinction of roles assigned to women and men. The texts published at the time reveal changes and continuities in the Catholic discourse in its reference to "nature", understood in its biological materiality, as an unswerving fact of human reality, consisting in two sexes must unite under the "natural order". Gender theories are blamed by family disintegration, for providing support to new understandings of humanity, no longer based on bipolarity: men / women. A non extensive dossier of these texts formed the basis for the proposed analyzes.
\end{abstract}

Key words: gender ideology; religious conservatism; Catholicism; National Education Plan; natural order

\footnotetext{
Agradeço ao CNPq o apoio para a realização da pesquisa da qual resulta o presente artigo.

Artigo recebido em: 05 de maio de 2015 e aprovado em 25 de setembro de 2015.

*Socióloga, doutora pela École des Hautes Études en Sciences Sociales, Paris. País de Origem: Brasil. E mail: mjrosado@uol.com.br
} 
Les études de genre posent-elles problème au catholicisme ou sont-elles particulièrement révélatrices de ce qui pose problème au catholicisme? Anthony Favier $\mathrm{n} .{ }^{1}$

\section{Introdução}

$\mathrm{O}$ trabalho de pesquisa faz-nos muitas vezes surpresas interessantes. Na busca por investigações sobre o tratamento de gênero pela igreja Católica, depareime com algumas referências de textos franceses. Dois deles chamaram-me-me particularmente a atenção: La réception catholique des études de genre. (FAVIER, 2014) e L'Église Catholique contre "la théorie du genre": construction d'um objet polemique dans le débat public français contemporain. (CARNAC, Romain, 2014) Do primeiro extraí a epígrafe acima. Inicio este artigo com algumas das ideias aí apresentadas, por julgá-las pertinentes para uma aproximação com o presente texto. Neste, a partir de uma pesquisa exploratória sobre a reação católica ao PNE - Plano Nacional de Educação, discute-se como o gênero, tomado como um conceito homogêneo, é considerado um poderoso inimigo, destruidor dos valores morais defendidos pela Igreja Católica.

Anthony Favier (2012) aponta que, de início, as reivindicações feministas relativas à igualdade de direitos com os homens na vida pública, no trabalho e na vida privada e contra a redução das mulheres às funções maternais e domésticas foram seja combatidas pela hierarquia católica, seja acolhidas com relativa indiferença. A razão do combate e da indiferença radicaria, para o autor, no fato de serem devedoras de correntes de pensamento estranhas, ou mesmo hostis ao Catolicismo: o Existencialismo e o Marxismo. Haveria, no entanto, uma outra vertente da recepção católica do gênero, positiva, ainda que marginal, encontrada em trabalhos de teólogas e escritoras. No caso do Brasil, também encontramos

\footnotetext{
1 "Os estudos de gênero fazem problema ao Catolicismo ou são particularmente reveladores daquilo que faz problema para o Catolicismo?". Todas as traduções de textos estrangeiros são da autora do artigo.
} 
intelectuais e agentes religiosos em especial do campo cristão - Catolicismo e Protestantismo - que tem nos estudos de gênero uma referência para seus textos. ${ }^{2}$

No entanto, como mostra Favier (2012, p. 5) na sequência do artigo, a partir do início dos anos 90, no marco das Conferências Internacionais de Cairo e Beijing, respectivamente em 1994 e 1995, a hierarquia católica passa a combater os estudos feministas e as teorias de gênero, de forma sistemática. Essa condenação é explícita em documentos oficiais da Santa Sé. A incorporação do termo "gênero" nos textos finais dessas conferências da ONU é considerada uma ameaça, pois amplia a compreensão da identidade sexual, que pode assim, ser adaptada indefinidamente a fins novos e distintos. O que está em questão nesse pensamento católico são as consequências da desconstrução realizada pelas teorias de gênero da ideia da natureza como um absoluto, para os conceitos tradicionais de sexo e de família3.

Como no caso dos debates em torno do PNE, em nosso país, objeto deste artigo, Favier analisa o lugar ocupado pelas teorias de gênero na querela dos manuais escolares na França. Nas palavras do porta voz da Conferência Episcopal da França: “aqueles que se opõem ao gênero não negam o impacto dos modelos sociais na interpretação de si. Mas dizem que é profundamente ambíguo privilegiar o gênero como pura construção social sobre a diferença sexual.” (FAVIER, 2012, p. 18, n.63).

Romain Carnac (2014) vê nessa construção discursiva do gênero pela igreja católica uma estratégia para ganhar visibilidade no espaço público. O gênero é

\footnotetext{
${ }^{2}$ Uma das mais reconhecidas nacional e internacionalmente é Ivone Gebara, teóloga católica que tem uma produção considerável de artigos e livros publicados no Brasil e no exterior.

${ }^{3}$ No campo da educação, várias autoras, entre elas Guacira Louro (2001; 2004) e Marília Carvalho (2011), têm discutido as variações sofridas pelo conceito de gênero e sua importância na construção não fixista de identidades. Jane Felipe (2007: 78-79) afirma: “[...] cabe ressaltar a produtividade do conceito de gênero como ferramenta teórica e política na reflexão a respeito das subalternidades, abalando certezas tão firmemente alicerçadas em torno das diferenças biológicas, que serviram durante muito tempo para justificar as desigualdades entre homens e mulheres. a consolidação dos estudos de gênero, dos estudos gays e lésbicos e da teoria queer no campo acadêmico traz a possibilidade de pensar que existem muitas formas de viver as masculinidades e as feminilidades e que estas são construções sociais e culturais, elaboradas minuciosamente por inúmeros discursos, áreas de conhecimento e instituições (LOURO, 2001; 2004). Seria, portanto, produtivo pensar no exame das práticas sociais e culturais que, através de seus diferentes discursos religioso, jurídico, médico, psicológico, pedagógico - constituem homens e mulheres, meninos e meninas, limitando-os, muitas vezes, em suas experiências".
} 
construído como o grande inimigo contra o qual devem unir-se, não apenas católic@s, mas tod@s aquel@s que defendem valores “humanistas”, especialmente a família entendida unicamente em sua realização heterossexual. A igreja pretende assim, atingir uma audiência ampla, que ultrapassa o universo de seus e suas fieis apenas. Negando cientificidade às teorias de gênero, apresentadas sempre como unívocas - "a teoria de gênero" - e falsamente libertadoras, estas revertem o curso normal da natureza, negando que os seres humanos dividem-se em dois sexos. Carnac vê ainda nesse investimento da igreja contra o gênero, a reafirmação de sua posição anti-moderna. Ela recusa a pretensão à autonomia individual, negadora da necessária submissão às leis da natureza, de origem divina. Nega legitimidade à validação das normas reguladoras da sexualidade pela deliberação coletiva, própria dos processos democráticos. Para o autor, na controvérsia em torno do gênero, “o discurso da Igreja aparece mais intransigente que nunca". (CARNAC, 2014, p. 143).

Essa condenação do gênero e a reafirmação da referência às leis da natureza para explicar e reafirmar as diferenças entre mulheres e homens e justificar o controle destes, reconhecidas e analisadas pelos autores referidos acima, perpassa também, no Brasil, o discurso da hierarquia e de outros atores católicos no caso das discussões em torno do $\mathrm{PNE}^{4}$, como se verá a seguir.

\section{Atores e discursos em disputa em torno do Plano Nacional de Educação - PNE}

O Plano Nacional de Educação (PNE) teve uma longa e conturbada trajetória. Entregue ao Presidente Lula pelo Ministro da Educação à época, Fernando Haddad, em 15 de dezembro de 2010 foi encaminhado à Câmara d@s Deputad@s, que o aprovou quase dois anos mais tarde, em outubro de 2012, após ter recebido cerca de três mil emendas. Passou pelo Senado e em dezembro de

\footnotetext{
${ }^{4}$ O Plano Nacional De Educação será referido neste texto peela sigla PNE.

${ }^{5}$ Para a elaboração deste texto foi constituído um dossiê com 44 matérias, relativas a manifestações públicas de posições contrárias e favoráveis à redação original do PNE. Tais matérias foram publicadas entre outubro de 2011 e agosto de 2014, em diferentes veículos. Trata-se de uma pesquisa exploratória, não exaustiva, portanto.
} 
2013 foi encaminhado à Comissão Especial da Câmara, onde foi aprovado no dia 22 de abril de 2014. Após esse trâmite, o PNE foi, então, encaminhado à Presidenta da República, Dilma Roussef, que o sancionou sem vetos, no dia 25 de junho. O Plano define diretrizes e metas para a educação até 2020 e é fruto de longa discussão e intensos debates na Câmara e no Senado, assim como entre educador@s de todo o país.

Além das discussões sobre maior investimento do governo no financiamento do ensino público pela destinação de verbas com uma porcentagem significativa dos recursos de fundos públicos - para a educação e outras, a inclusão da referência às desigualdades de gênero e à diversidade ocuparam o centro da polêmica. O texto do relator, deputado Angelo Vanhoni (PT-SC) propunha estimular "a superação das desigualdades educacionais, com ênfase na promoção da igualdade racial, regional, de gênero e de orientação sexual”. No correr das votações no Congresso, o texto acabou alterado e a redação final aprovada refere genericamente: “a superação das desigualdades educacionais, com ênfase na promoção da cidadania e na erradicação de todas as formas de discriminação”. Os debates em torno do PNE deram-se no contexto de outras discussões em relação a direitos de cidadania, como lembram Carla Batista e Márcia Laranjeira:

Este (educação e gênero) foi um tema candente no primeiro semestre de 2014, a partir da discussão do Plano Nacional de Educação (PNE). Veio na sequência de dois outros importantes momentos que mobilizaram os movimentos sociais: do campo feminista, LGBTs e em defesa de uma educação laica e pluralista: a assinatura do acordo entre o Brasil e o Vaticano, em 2009, e a suspensão, em 2011, da distribuição do chamado Kit Anti-homofobia nas escolas públicas (BATISTA; LARANJEIRA, 2014, p.96).

Grupos religiosos, especialmente católicos e evangélicos, foram os atores mais fortemente ativos nesse processo de apresentação e votação do PNE. No Boletim do CLAM - Centro Latino-Americano em Sexualidade e Direitos Humanos -, de 30 de abril de 2014, em matéria intitulada: Por que o gênero assusta tanto? lê-se: 
A supressão das referências às desigualdades de gênero e ao respeito à orientação sexual é efeito da pressão de setores religiosos conservadores que, incomodados com práticas pluralistas que contradizem seus valores morais, têm dificultado, no âmbito da educação, o desenvolvimento de políticas em nome dos direitos das mulheres, dos direitos sexuais e reprodutivos, assim como qualquer medida no marco dos direitos humanos. (CLAM, 2014, s/p.).

Análises semelhantes podem ser lidas em manifestações de parlamentares, intelectuais e grupos organizados, durante o processo de discussão do PNE. Em caráter apenas ilustrativo, três exemplos, a seguir. Adriano Souza Senkevics pesquisador do Instituto Nacional de Estudos e Pesquisas Educacionais Anísio Teixeira (Inep), em artigo sobre o PNE e a "ideologia de gênero", diz:

Setores conservadores, mobilizados por políticos fundamentalistas, têm se oposto à votação do PNE em razão de sua menção à "igualdade de gênero". Nos termos dos obscurantistas, tratar-se-ia de uma "ideologia de gênero". [...] Esses grupos temem pela "destruição da família", os "valores e morais" alicerçados na "lei natural" e, evidentemente, o avanço das pautas LGBT, dentre as quais a diversidade sexual, a criminalização da homofobia e o progresso em torno da despatologização do segmento trans $^{*}$ - pontos, na verdade, que transcendem a escola. (ENSAIOS DE GÊNERO, 2014, s/p.).

\section{O deputado Jean Willys assim se expressou:}

Há três anos nos debruçamos na construção de um Plano Nacional de Educação que finalmente diga que a escola é um lugar de inclusão, de superação das desigualdades educacionais, com ênfase na promoção da igualdade racial, regional, de gênero e de orientação sexual. A redação proposta pelo relator foi construída com movimentos sociais, organizações da sociedade civil, entre outros grupos, ao longo desses três anos de discussão. Apesar disto, parlamentares ligados a grupos religiosos se opõem a este trecho do projeto e fazem uma suja manipulação das informações a fim de colocar a população contra esta iniciativa. (IG GAY, 2014, s/p.).

O Núcleo de Estudos e Pesquisas em Gênero e Sexualidade, Ser-Tão, demonstrou publicamente em nota seu descontentamento com a retirada de questões relacionadas às desigualdades raciais, regionais, de gênero e sexuais do PNE e sua preocupação com 
os significados e efeitos que a cessão às pressões de determinados setores religiosos conservadores, apoiados em uma visão de mundo heterocentrada, racista, misógina e homo-lesbo-transfóbica, tem para o documento, para o campo da Educação e para a vida social em geral, no Brasil (SER-TÃO, 2014, s/p.).

Os textos acima, assim como muitos outros não referidos neste artigo, mas facilmente encontráveis pela internet e em jornais da época, identificam nos "setores religiosos conservadores" os opositores mais fortes e organizados contra o PNE. Para estes, o que denominam como "ideologia de gênero" seria responsável pelos "erros" contidos no documento. Ativistas contrários à inclusão de gênero e dos direitos LGBT presentes à sessão da Comissão especial sobre o PNE, da Câmara dos Deputados que apreciou e votou o projeto de lei, portavam cartazes de explícito repúdio à “ideologia de gênero". Alguns deles diziam: "Gênero não!" ou "Não à ideologia de gênero!". A matéria do CLAM citada acima afirma: "O incômodo é direcionado à possibilidade de se pensar as relações de gênero e sexualidade fora do marco religioso". É desse incômodo que tratará o presente texto, discutindo especificamente as complexas relações do Catolicismo com o sexo, la part maudite, expressão com a qual a historiadora francesa Michèle Perrot abre suas considerações, em livro que trata de religião e sexualidade:

A recusa de uma sexualidade/prazer, equiparada ao pecado, ou mesmo o pecado por excelência, parece quase fundadora do Cristianismo, pelo menos com os Pais da Igreja, especialmente Agostinho e Jerônimo, que expressam uma viva repugnância em relação ao comércio carnal (2002, p.193).

\section{A Igreja Católica contra "a ideologia de gênero"}

Analisando os ataques recentes da Igreja Católica na França às teorias de gênero, Alain CARNAC (2014) mostra como estas se tornam um "inimigo imaginário", construído pelo discurso católico, amplamente mediatizado e difundido. Essa estratégia discursiva permite à Igreja reformular suas críticas ao mundo moderno e reafirmar certos pontos doutrinais. 
No contexto da apreciação e votação do PNE pelo Congresso Nacional, em um momento crítico da discussão pública sobre o mesmo, D. Orani Tempesta, cardeal e arcebispo do Rio de Janeiro, escreve um artigo com o título Reflexões sobre a "ideologia de gênero" (CNBB, 2014). No site da CNBB, o artigo aparece no dia 28 de março de 2014, após a votação do projeto na Câmara d@s Deputad@s. Porém o blog “O povo” (2014) publica matéria comentando o texto do cardeal, na véspera dessa votação. Lê-se aí: "O texto é fruto da reunião plenária da União dos Juristas Católicos do Rio de Janeiro (UJURCAT-RJ) com o purpurado ocorrido na última segunda-feira, 24. A assembleia aprovou por unanimidade posição contrária a (sic) inserção do termo 'gênero' e da expressão ‘orientação sexual' como princípio e/ou diretriz do Plano Nacional de Educação - PNE”. A matéria do blog assinada por Vanderlúcio Souza, que se apresenta como “católico, engajado na igreja desde a infância”, termina com um apelo à ação política não apenas da população católica, mas de todos que "receberam esta mensagem que telefonem e enviem mails aos Deputados que irão votar o Plano Nacional de Educação no dia 26 de março." E continua: "Entrem também em contato com os professores de seus filhos. Peçam que eles se manifestem junto à Câmara." (negritos no original).

O texto de D. Orani é citado em vários artigos de grupos católicos contrários à aprovação do PNE tal como apresentado pelo relator, i.e., com a inclusão da referência a gênero e à orientação sexual. Em termos internos à Igreja Católica, na hierarquia eclesiástica, D. Orani ocupa um lugar destacado, como cardeal. Esse título confere ao clérigo um capital simbólico e real considerável, pois torna-o membro do colégio cardinalício que tem assento em Roma, em momentos cruciais para a instituição, como no da escolha de um novo Papa.

Para fins deste artigo, tomou-se então, essa manifestação pública do cardeal para buscar compreender as razões pelas quais o gênero é tratado como uma "ideologia" incômoda para grupos conservadores, religiosos ou não, e, em particular, para a Igreja Católica. O texto em questão pode servir como uma espécie de paradigma, condensando os argumentos que expressam a lógica 
institucional no tratamento de duas questões cruciais para ela: a sexualidade e a concepção de natureza humana. Antes, porém, de analisar essa problemática no discurso eclesiástico, convém interrogar como o "gênero" no discurso da igreja aparece como "ideologia de gênero", merecendo explícito repúdio. O cardeal Angelo Bagnasco, Arcebispo de Gênova e presidente da Conferência Episcopal Italiana, utiliza a expressão “ditadura do gênero" e convida os pais a rebelar-se contra ela:

Uma "verdadeira ditadura" esta da 'ideologia' de gênero. É imposta à escola, transformando-a, assim, em 'campos de reeducação'. Isto pensa o cardeal Bagnasco - foi o que disse ao Conselho Permanente da CEI, em 24 de março passado, sobre a iniciativa de se difundir na escola três documentos destinados ao primário e ao secundário: "Educar para a diversidade.” Tais publicações são parte das estratégias governamentais italianas anti-homofobia (ADISTA ONLINE, 05 de abril de 2014).

Nas palavras do Cardeal:

É a leitura ideológica do 'gênero' uma verdadeira ditadura que quer anular a diversidade, homologar tudo até tratar a identidade do homem e da mulher como puras abstrações. É de perguntar-se com amargura se se quer fazer da escola 'campos de reeducação', de 'doutrinação'. Mas os pais ainda têm o direito de educar os próprios filhos, ou foram desautorizados de fazê-lo? Pediu-se a eles não apenas consentimento, mas antes a permissão explícita? Os filhos não são materiais de experimentação nas mãos de ninguém, nem mesmo de técnicos ou de ditos especialistas. Os pais não se deixem intimidar, têm o direito de reagir com determinação e clareza: não há autoridade que tenha esse direito (ADISTA ONLINE, o5 de abril 2014, s/p.).

D. Orani (CNBB, 2014) menciona uma Nota da Conferência Episcopal do Peru, de abril de 1998 que, desde o título, alerta para os efeitos perniciosos dessa "ideologia" de raiz marxista e ateia: "La ideologia de género: sus peligros y alcances". Retomando essa nota, o cardeal afirma que "o sistema ideológico de gênero" impõe a homens e mulheres comportamentos em desacordo com "a natureza". Nega, desta forma, "o instinto natural" das meninas à maternidade e aos homens, sua "necessidade de trabalhar fora de casa a fim de melhor sustentar a família”. 
A nota da Conferência dos bispos do Peru talvez seja a primeira referência de um organismo oficial da igreja ao que vários documentos posteriores passarão a denominar "ideologia de gênero"6. Logo de início, na apresentação, lê-se:

Tem-se ouvido durante estes últimos anos a expressão "gênero" e muitos imaginam que é apenas uma outra maneira de se referir à divisão da humanidade em dois sexos. Porém, por detrás desta palavra se esconde toda uma ideologia que pretende, precisamente, modificar o pensamento dos seres humanos acerca desta estrutura bipolar. (VERITATIS, 2008, s/p.).

Segundo o Conselho Pontifício para a Família, a difusão da "ideologia de gênero" não pode ser subestimada em seu poder desestruturador da instituição matrimonial. O documento do Conselho, "Família, matrimônio e "uniões de fato", de 26 de julho de 2000, alerta para as bases individualistas e liberais da antropologia que fundamenta essa ideologia, assim como para sua sustentação pelo feminismo. $\mathrm{O}$ item 8 do documento afirma:

Dentro de um processo que se poderia denominar de gradual desestruturação cultural e humana da instituição matrimonial, não deve ser subestimada a difusão de certa ideologia de "gênero" ("gender"). Ser homem ou mulher não estaria determinado fundamentalmente pelo sexo, mas pela cultura. Com isto se atacam as próprias bases da família e das relações interpessoais. É preciso fazer algumas considerações a este respeito, devido à importância desta ideologia na cultura contemporânea e de sua influência no fenômeno das uniões de fato. [...] A ideologia de "gender" encontrou na antropologia individualista do neo-liberalismo radical um ambiente favorável[7]. A reivindicação de um estatuto semelhante, tanto para o matrimônio como para as uniões de fato (inclusive as homossexuais), costuma hoje em dia justificar-se com base em categorias e termos procedentes da ideologia de "gender" (VATICANO, 2000, s/p.).

As notas explicativas 6 e 7 do documento são ilustrativas da concepção de "gênero" de que fala o documento. Vejamos: Nota 6:

Diversas teorias construcionistas sustentam hoje em dia concepções diferentes sobre o modo de como a sociedade teria - a seu parecer - que mudar adaptando-se aos distintos "gender" (pense-se, por exemplo, na

\footnotetext{
${ }^{6}$ Em nossa busca, ainda que não exaustiva, não conseguimos identificar outro documento da hierarquia eclesiástica anterior a este, que mencionasse a "ideologia de gênero".
} 
educação, saúde, etc.). Alguns admitem três gêneros, outros cinco, outros sete, outros um número distinto de acordo com diversas considerações (VATICANO, 2000, s/p.).

E a nota 7 completa:

Tanto o Marxismo como o estruturalismo contribuíram em diferente medida para a consolidação da idéia de "gender", que sofreu variadas influências, tais como a "revolução sexual" (...) Um certo feminismo radicalizado e extremista, representado pelas contribuições de Margaret Sanger (1879-1966) e Simone de Beauvoir (1908-1986), não pode ser situado à margem deste processo histórico de consolidação de uma ideologia. (VATICANO, 2000, s/p.).

Voltaremos, à frente, a esse documento, para analisar as razões pelas quais gênero apresenta-se hoje, para a Igreja Católica como uma frente de combate das mais importantes.

Em 2013, a Conferência Episcopal Portuguesa divulga uma carta pastoral com o título "A Propósito da ideologia de gênero". Como a carta dos Bispos do Peru, esta inicia-se invocando o desconhecimento das pessoas sobre o que verdadeiramente é o gênero e apontando seus efeitos perversos para a sociedade. Dizem os prelados:

Difunde-se cada vez mais a chamada ideologia do género ou gender. Porém, nem todas as pessoas disso se apercebem e muitos desconhecem o seu alcance social e cultural, que já foi qualificado como verdadeira revolução antropológica. Não se trata apenas de uma simples moda intelectual. Diz respeito antes a um movimento cultural com reflexos na compreensão da família, na esfera política e legislativa, no ensino, na comunicação social e na própria linguagem corrente (APOSTOLADO DA ORAÇÃO, 2013, s/p).

Voltando ao texto de D. Orani Tempesta, este pretende esclarecer o que é a "ideologia de gênero", supondo também seu desconhecimento por parte da população a ela submetida pelos poderes dominantes. Diz ele: 
A "revolucionária" ideologia de gênero vem tentando se implantar no Brasil por meio de grandes esforços do poder reinante ou dominante. Diante desta situação, incumbe-nos, enquanto brasileiros e cristãos, saber o que é essa ideologia muito comentada, mas pouco definida, quais são suas raízes, como ela se impõe, que objetivos tem e qual deve ser a nossa posição frente a ela. (CNBB, 2014, s/p.).

$\mathrm{O}$ argumento inicial é formulado negativamente, explicitando o "sistema ideológico" de gênero como destruidor da "natureza humana". Na perspectiva de gênero "não existiria uma mulher ou um homem naturais [...], nada dependeria da natureza, mas sim de uma construção sociocultural". A "natureza" é definidora não apenas de características anátomo-biológicas, mas de papeis sociais distintos:

se o homem brinca de bola e sente necessidade de trabalhar fora de casa a fim de melhor sustentar a família ao passo que as mulheres preferem, via de regra, passar mais tempo em casa junto aos filhos [...], não estariam, de modo algum, atendendo a seus anseios inatos, mas apenas se acomodando ao desejo elitista de uma tradição opressora que deve ser rompida a qualquer momento. (CNBB, 2014, s/p.).

Gênero seria uma forma de "apagar as diferenças naturais entre homem e mulher". Em consequência, a destruição da família pela defesa da "liberdade de construção sexual", da "autoconstrução livre da própria sexualidade" aparece como um segundo elemento presente na argumentação do texto. Em lugar do "matrimônio monogâmico e estável com bases religiosas", haveria diversos "tipos de casamento".

Diferentemente de uma literatura religiosa conservadora que prefere recorrer a argumentos de caráter científico e jurídico, D. Orani se refere à doutrina católica e aos valores morais cristãos em termos da defesa da "força sobrenatural da Igreja" (VAGGIONE; MUJICA, 2013).7 Esta estaria sendo duramente atacada pela ideologia de gênero que "[...] fecha sua carranca e ataca-nos impiedosamente para destruir a vida, a família e os valores sociais alicerçados na lei natural moral" (CNBB, 2014, s/p.). Na avaliação do Cardeal, a disseminação dessa ideologia

\footnotetext{
7 Juan Marco VAGGIONE e Jaris MUJICA (2013, p.17-40), em recente publicação sobre o conservadorismo religioso na América Latina, mostram as mudanças ocorridas nas estratégias dos grupos conservadores na região. Estas renovaram-se pela secularização do discurso e por formas diferentes de presença e atuação no espaço público.
} 
"revolucionária e perversa" se daria por sua força junto aos meios de comunicação e por sua difusão no sistema educacional formal.

Os elementos encontrados nesse texto estão presentes naqueles que reunimos como base para o presente artigo, citados anteriormente, e os que referiremos a seguir.

Em recente documento emanado do Vaticano, com data de publicação de 24 de junho de 2014, há várias referências à “ideologia de gênero"(SÍNODO DOS BISPOS). O documento intitulado "Os Desafios pastorais da família no contexto da evangelização. Instrumentum Laboris" apresenta os resultados de uma ampla consulta enviada ao "povo de Deus", dioceses e paróquias de todo o mundo, na forma de um questionário intitulado "Documento preparatório". A consulta, feita a pedido do atual Papa, Francisco, teve como objetivo colher informações a respeito da opinião de fiéis e clero sobre temas relativos à "família", já que se destinava a preparar o Sínodo Extraordinário dos Bispos, a realizar-se em Roma, em outubro deste ano, cujo tema é justamente “a família” sempre no singular. No capítulo III, da I parte, "Evangelho da família e lei natural", ao tratar da "Problemática da lei natural hoje”, no item 23 que fala sobre "direitos humanos”, o documento diz:

Neste contexto, encontra-se a crescente difusão da ideologia chamada gender theory, segundo a qual o gender de cada indivíduo resulta ser apenas o produto de condicionamentos e necessidades sociais, deixando, deste modo, de ter plena correspondência com a sexualidade biológica. (SÍNODO DOS BISPOS, 2014, p.39).

Note-se que, ao menos na tradução brasileira que utilizamos, ao tratar gênero com uma conotação negativa, a palavra aparece em itálico e em inglês. Não seria abusivo pensar o uso do termo em inglês como uma forma de remeter o pensamento e as propostas políticas vinculadas a gênero, à influência dos Estados Unidos, uma imposição cultural alheia a outros países e culturas, como aparece em certos discursos católicos. Anthony Favier (2012, p.8) faz observação semelhante, ao indicar "a vontade de manter a palavra em inglês". 
Já no item 26, encontramos "gênero", agora afirmativamente, sem conotação "ideológica", mas como um "fato": "Das respostas emerge a convicção generalizada do "fato" de que a distinção dos gêneros possui um fundamento natural no âmbito da existência humana”.

Quando trata da união entre pessoas do mesmo sexo, na parte II: "A Pastoral da família diante dos novos desafios”, o item 114 inclui a ideologia de gênero entre os fatores que dificultam o trabalho pastoral:

Um fator que indubitavelmente interroga a ação pastoral da Igreja e torna complexa a busca de uma atitude equilibrada em relação a esta realidade é a promoção da ideologia do gender, que em algumas regiões tende a influenciar até o âmbito educacional primário, difundindo uma mentalidade que, por detrás da ideia de remoção da homofobia, na realidade propõe uma subversão da identidade sexual. (SÍNODO DOS BISPOS, 2014, p.100-101).

O mesmo tom acusatório do gênero como algo que subverte a ordem "natural" a que remete a ideia de uma identidade sexual será repetido em item posterior, assim como os vínculos do gênero a uma educação que não respeita a “diferença sexual”.

De modo cada vez mais urgente, apresenta-se o desafio da educação sexual nas famílias e nas instituições escolares, particularmente nos países onde o Estado tende a propor, nas escolas, uma visão unilateral e ideológica de gênero, (item 119 In: SÍNODO DOS BISPOS, 2014, p. 102103).

Elencando os “desafios pastorais acerca da abertura à vida”, no capítulo I, da III parte, o texto volta à ideologia, no item 127:

Em algumas respostas comparam-se a difundida mentalidade contraceptiva com a presença maciça da ideologia do gender, que tende a modificar algumas estruturas fundamentais da antropologia, entre as quais o sentido do corpo e da diferença sexual, substituída pela ideia da orientação de gênero, a ponto de chegar a propor a subversão da identidade sexual. (SÍNODO DOS BISPOS, 2014, p.111). 
O texto continua com um chamado à ação:

\begin{abstract}
A este propósito sobressai, de muitas partes, a necessidade de ir mais além das condenações genéricas contra tal ideologia cada vez mais invasiva, para responder de maneira fundada a tal posição, hoje amplamente difundida em muitas sociedades ocidentais. Neste sentido, o descrédito atribuído à posição da Igreja em matéria de paternidade e maternidade constitui apenas um elemento de uma transformação antropológica que algumas realidades muito influentes (sic) continuam a promover. (SÍNODO DOS BISPOS, 2014, p.111).
\end{abstract}

Esse documento do Vaticano que apresentou a todo o mundo católico os resultados do questionário recebeu fortes críticas de católicos que manifestaram seu desacordo com as análises aí sugeridas (SBARDELOTTO; ADISTA, 2014). Essas reações, que não são o objeto deste texto, são uma das expressões da diversidade interna ao Catolicismo. Daí a necessidade teórica e prática, ao se tratar da Igreja Católica, de referir o conservadorismo a setores cujo discurso e prática revelam posições de resistência aos direitos sexuais e reprodutivos. O Catolicismo, como bem indicou Émile Poulat, deveria, na verdade, ser referido sempre no plural - Catolicismos - dada a diversidade de pensamentos e de práticas pastorais que o constituem. Está longe de ser um bloco homogêneo.

Favier (2012, p.19) se refere também a essa diversidade interna e as reações de setores "mais intelectuais" que buscam discernir nos estudos de gênero, o que poderia ser absorvido no Catolicismo.

\title{
3 O "perigo" da "vergonhosa ideologia de gênero" para a Igreja Católica
}

Não seria possível, nos limites deste artigo, desenvolver as ricas análises existentes sobre a crise do modelo católico em relação à moral sexual e à sua compreensão do lugar social, político e cultural das mulheres, nas sociedades contemporâneas. O presente texto sugere apenas algumas razões pelas quais a "vergonhosa ideologia de gênero" constitui-se no discurso religioso como uma verdadeira e poderosa ameaça. Os argumentos centrais para o tratamento negativo 
de gênero como uma ideologia perniciosa vinculam-se às suas concepções sobre a moral sexual e reprodutiva, e, por consequência, sobre família, alicerçadas em sua compreensão da "natureza humana”. A estrutura organizacional católica assentase em relações de poder hierárquicas e androcêntricas, construídas sobre diferenças sexuais consideradas definitivamente marcadas pela biologia. As proposições feministas ancoradas em uma perspectiva de gênero ou de relações sociais de sexo como prefere parte das especialistas francesas, questiona e desconstrói essa visão fixista e biologizante da natureza humana ${ }^{8}$. Tal desconstrução afeta fortemente o edifício real e simbólico católico. Diz Michelle Perrot:

Colocarei, em seguida, a questão do gênero. No sentido em que a pesquisa feminista a compreende atualmente, a saber, a diferença dos sexos tal qual é construída pela cultura e pela história, esta, sem dúvida, não tem grande sentido para a Igreja, que não cessa de reafirmar o primado de uma "natureza" querida por Deus e criada por ele, fundamento de sua teologia moral e sexual (PERROT, 2002, p.195)9.

Uma hipótese, pois, que orienta este texto, é que o conceito de "natureza humana" como decorrente de uma "lei natural" dada por Deus, comprovada pela biologia e inalterável é peça fundamental na argumentação que sustenta a condenação do gênero qualificado como uma "ideologia", com forte conotação negativa $^{10}$. Os textos referidos e citados acima sobre o PNE reiteram que a “ideologia de gênero" fere a "natureza”, desrespeita as leis divinas. Retomando o documento do Pontifício Conselho para a Família, vê-se, por exemplo, que a “identidade de gênero" é perniciosa à instituição do matrimônio porque destrói as

\footnotetext{
${ }^{8}$ Naara Luna analisa o discurso católico sobre a natureza, em 2 interessantes artigos: Aborto e células-tronco embrionárias na Campanha da Fraternidade e As novas tecnologias reprodutivas e o estatuto do embrião: um discurso do Magistério da Igreja Católica sobre a Natureza.

9 "Je poserai ensuite la question du genre. Au sens où l'entend actuellement la recherche féministe, à savoir la différence des sexes telle qu'elle est construite par la culture et par l'histoire, cela n'a sans doute pas grand sens pour l'Église, qui ne cesse de réaffirmer le primat d'une 'nature' voulue par Dieu et créée par lui, ancrage de sa théologie morale et sexuelle».

${ }^{10}$ Éléni Varikas em texto sobre "direito natural" discute proposições feministas que se referem também a uma "natureza feminina". Como nota a autora: A referência à natureza não é exclusiva do discurso religioso. Em busca de resultados opostos - emancipação das mulheres - também no feminismo encontram-se tais referências. VARIKAS, Éleni. Droit naturel, nature féminine et égalité des sexes. In : L Homme et la société, n.85-86, 1987. p.110-111. No Brasil, Bila Sorj faz uma crítica ao "feminismo da diferença»: "Finalmente, a ênfase na dimensão natural do feminino deve ser tratada com muita cautela porque foi justamente ao redor desta ideia que se construiu um sistema de discriminações e exclusões, não apenas com relação ao gênero como também à raça e a vários povos. Mais ainda, atribuir ao natural uma dimensão absolutamente virtuosa é partilhar de uma visão romântica que desconhece que a natureza tanto pode ser fonte de vida como de morte, de criação como de destruição, de prazer como de sofrimento. (Bila SORJ, 1992, p.150).
} 
bases da família: Desconstrói a relação do "ser homem e ser mulher” ao sexo e dá igual estatuto a uniões hétero e homossexuais. Ao entender as diferenças entre os sexos como resultado de construção cultural e social, as proposições que tomam gênero como uma categoria de compreensão das relações estabelecidas entre mulheres e homens na sociedade, fogem a esse determinismo biológico e libertam as mulheres do peso da maternidade como destino irrevogável imposto pela "natureza". Tal compreensão atinge de maneira particular o coração mesmo do conceito de família, no singular, tal como entendido e reiterado pela Igreja. Isto porque ao desconstruir a ideia de que os seres humanos são devedores de uma "lei" vinda do alto, o que os obriga, especialmente à população feminina, a segui-la, reconfigura-se o dispositivo familiar, que passa a fundar-se na vontade $\mathrm{d} @ \mathrm{~s}$ indivídu@s e no contrato entre el@s. Isso é possível às mulheres, uma vez que o acesso generalizado às práticas contraceptivas lhes permite a livre disposição de si, um valor tipicamente moderno, amplamente assimilado como um direito individual.11 Seguindo as análises de Danièle Hervieu Léger (2003, p. 168s.), o reconhecimento social do direito das mulheres a controlar a própria capacidade de fazer novos seres humanos rompe “[...] o dispositivo de imputação das mulheres à 'lei da natureza' que serve para justificar, desde a noite dos tempos, a inferioridade social da mulher, seu encerramento doméstico e sua submissão à dominação masculina” (p.189). Mesmo as conquistas no campo legal não poderiam ter pleno efeito a não ser a partir do momento em que "a maternidade deixou de ser um destino natural transfigurado em uma vocação sagrada para tornar-se uma escolha”. Diz ela:

As mulheres são as primeiras a fazer a experiência de que a natureza não é mais uma ordem. Isso é uma revolução enorme, à qual as pesquisas fazem pouca ou nenhuma referência. Essa experiência, diz ela, em poucos anos, arrancou uma ou duas gerações de mulheres, ainda socializadas em um catolicismo da submissão (ao padre, ao marido, a Deus e à natureza), a uma concepção - no entanto profundamente interiorizada - da

\footnotetext{
${ }^{11}$ Cf. os excelentes capítulos 4, 5 e 6 do livro de HERVIEU-LÉGER, Daniéle. Catholicisme, la fin d'un monde. Paris: Bayard, 2003, sobre os impasses para o Catolicismo da realização pessoal defendida como um valor a ser buscado; das novas formas de regulação das relações familiares e da negação da compreensão da natureza como "ordem" absoluta. Capítulo 4: De la réalisation de soi dans une societé où s'efface la peur de manquer. La prédication catholique de l'accomplissement dans l'impasse, p.132-167; Capítulo 5: L'Église lâchée par la famille, p.168-212 e Capítulo 6: Quand la nature n'est plus un orde, p. 213-263.
} 
inelutabilidade do seu destino de mulheres, destinadas a gravidezes sucessivas ou a correr riscos pessoais consideráveis para escapar a elas. A desqualificação do discurso católico hoje, em matéria de sexualidade e de procriação, tem sua origem mais profunda nesse abalo sísmico invisível. (HERVIEU-LÉGER, 2003, p. 250).

Esse deslocamento para a afirmação de si e da própria autonomia altera as formas tradicionais de poder que regulam as relações familiares. O modelo patriarcal, hierárquico e vertical dessas relações tende a dar lugar a relações horizontais, de respeito aos direitos de cada integrante. Mesmo em um país como o Brasil, marcado pela persistência de uma cultura machista, de domínio dos homens, a difusão e ampla aceitação da lei que pune a violência contra as mulheres, ainda que praticada no contexto das relações familiares consideradas de âmbito estritamente privado, podem ser tomadas como um indicador de profundas mudanças. A força do ditado popular "Em briga de marido e mulher ninguém mete a colher" tanto tempo vigente como uma verdade, vai sendo diluída, lentamente que seja, pela aplicação da "Maria da Penha", nome dado à lei referida antes.

Para a Igreja, a fragilização do modelo tradicional de família sobre o qual se assenta o edifício mais que milenar de sua institucionalidade soa como o alarme que anuncia a sua própria fragilização. A manutenção do dispositivo familiar tal qual ela ajudou a modelar é crucial para a instituição. Diante do avanço dos ideais democráticos de sociedades que se regulam pelo contrato entre indivídu@s livres, a Igreja investe na defesa da moralidade social, política e individual. Apresentar-se como a guardiã da moral é uma de suas estratégias para que seu discurso e sua ação na esfera pública sejam recebidos e aceitos ${ }^{12}$.

\footnotetext{
${ }^{12}$ É a esse título, como uma instituição moralizadora, que a Igreja se mantém, ao menos em países da região, como uma instituição de forte legitimidade pública, ainda que seus preceitos em termos dos comportamentos individuais não sejam seguidos nem mesmo por grande parte de suas e de seus fieis.
} 


\section{Concluindo para além do texto:}

\section{O confronto entre o ideário feminista e o ideário católico}

Se o discurso feminista foi de início recebido com indiferença pela Igreja, como propõe Favier (2012), a proposição do gênero como um conceito explicativo das relações sociais construídas entre os sexos, tornou-se um inimigo maior, merecedor de intenso combate. Romain Carnac (2012), em texto intitulado "Le gender, ennemi imaginaire des catholiques?”, afirma: “A partir dos anos 2000, assiste-se a uma reação virulenta da Igreja Católica romana à corrente de pensamento do gênero"(CARNAC, 2012). O tratamento do gênero como uma "vergonhosa e perversa ideologia" afeta particularmente a população LGBT e as mulheres, de maneira geral. Concluo apresentando considerações relativas apenas aos direitos das mulheres. Não é difícil vislumbrar os embates com o pensamento feminista, produzidos pelas concepções veiculadas nos textos analisados acima. Tratar sexo e reprodução no registro dos direitos e da cidadania e não da submissão às leis da natureza, que o conceito de gênero permite, tem profundo significado, em termos de mudança cultural e política. O respeito a procedimentos democráticos que estabelecem normas pela deliberação coletiva funda sua legitimidade. Isso vale também para o campo da sexualidade e da reprodução, o que lhes confere caráter político. A busca por legalidade no campo da sexualidade e da reprodução contraria a lógica do controle, da repressão e da interdição vigentes no pensamento católico, expressa em sua moral sexual. Inclusive porque são os próprios sujeitos que "inventam” esses direitos, esse novo campo de legalidade. (ÁVILA, 2005)

O reconhecimento da autonomia dos indivíduos na condução de sua vida afetiva e sexual permanece no entanto, para o Catolicismo, um tema proibido, quando pensado fora do marco religioso. Vale lembrar, a provocativa interrogação de Michelle Perrot: 
Por que esta obsessão, e mesmo este ódio da carne, da sexualidade, e esta profunda desconfiança da mulher no Cristianismo? Desconfiança que informou toda a cultura ocidental judaico- cristã. Por que a sexualidade é, hoje, uma linha de defesa e de afirmação da Igreja, notadamente por parte de João Paulo II? [...] Tudo se passa como se a Igreja tivesse investido o sagrado na moral sexual, colocado o sexo no coração do religioso, para responder a esta religião do sexo que invade a sociedade contemporânea (PERROT, 2002, p.197,198).

Hervieu-Léger explica o investimento católico nas questões relativas à sexualidade e à família, pela necessidade da instituição de organizar sua própria reprodução social e ideológica e de continuar a exercer, pelo controle das consciências e dos corpos uma influência social e política que não lhe é mais permitida no âmbito público, em sociedades modernas regidas por Estados seculares democráticos.

a questão da contracepção, e mais amplamente, as questões de moral sexual tornaram-se a pedra angular do dispositivo pelo qual a Igreja procura defender, contra todas as evoluções das mentalidades e das práticas, não apenas uma concepção de autoridade emanada do alto que é a armadura de sua própria institucionalidade, como também a especificidade de uma relação ao mundo na qual inscreve-se sua rejeição da afirmação moderna das autonomias”. (LÉGER, 2007, p. 243).

A civilização do controle e do medo instaurada pelo Cristianismo, associada à repressão do prazer e à suspeita sobre o sexo é inseparável da desvalorização simbólica e social das mulheres. Mesmo se nos lembrarmos de que no matrimônio cristão, instituído no século XII pela Igreja, são os noivos que realizam o sacramento, havendo, portanto, o reconhecimento da capacidade das mulheres tanto quanto dos homens de expressarem sua vontade, a atribuição às mulheres de uma natureza própria cuja "essência" é a maternidade é um continuum no pensamento eclesial. As diferenças biológicas, constantemente invocadas, validam a atribuição das mulheres à esfera doméstica, reafirmando a legitimidade de sua exclusão da esfera pública e reiterando sua inferioridade social e política.

As profundas mudanças contemporâneas da compreensão do estatuto d@s indivíduos e de sua relação com "a natureza" colocam em questão as tentativas da Igreja de controle dos corpos e dos sexos, fazendo seu discurso sofrer uma 
profunda crise de plausibilidade, que se manifesta, especialmente, na disseminação das práticas contraceptivas e na sua legitimação social. Feminismo e Catolicismo entram assim, na arena do debate público, em campos discursivos opostos. O deslocamento radical das questões relativas à moral sexual e ao controle da reprodução humana ameaça concepções católicas tradicionais nesses campos. A apropriação pelas mulheres da afirmação da autonomia na condução de suas vidas leva-as a considerar-se, enquanto sujeitos sociais, cidadãs, com o direito de interferir também na esfera política da sociedade. E enquanto indivíduas, o de controlar sua sexualidade e sua capacidade reprodutiva. No campo dos direitos sexuais e dos direitos reprodutivos, a afirmação da autonomia individual propõese como ponto fundamental do exercício da liberdade e como inspiração básica para as disputas na área da legislação.

As concepções católicas sobre as mulheres expressas em sua resistência ao conceito de gênero continuam, assim, a diferir radicalmente daquele elaborado pelas mesmas mulheres. E entram em conflito com as reivindicações feitas por elas, quando estas invocam direitos em todos os âmbitos de suas vidas - privada e pública. A concepção das mulheres que a Igreja propõe, vinculada definitivamente à realização real ou espiritual da maternidade, define-as como seres para os outros. As características atribuídas a uma suposta "natureza feminina" - sensibilidade, delicadeza, capacidade de doar-se e de perdoar - numa escala que vai sempre delas para alguém, contrapõe-se frontalmente à afirmação do desejo de ser para si mesmas que as mulheres expressam. Como dizia, há anos, uma mulher católica líder de uma CEB - Comunidade Eclesial de Base) de S. Paulo: E eu, como mulher, como é que eu fico? (ROSADO-NUNES, 1994) 


\section{REFERÊNCIAS}

ADISTA. L'Instrumentum Laboris é uma delusione: I commenti del mondo católico statunitense. Adista Online, Roma, n. 26, 12 jul. 2014. Disponível em: < http://www.adistaonline.it/index.php?op=articolo\&id=54078\#sthash.vgW88pC1.dpuf > Acesso em 13 ago. 2014.

ADISTA. L'invito del card. Bagnasco: Genitori, Ribellatevi ala "Dittatura di Genere" instillata a scuola. Adista Online, Roma, n. 13, 05 abr. 2014. Disponível em: < http://www.adistaonline.it/index.phh?op=articolo\&id=53768 > Acesso em o6 jul. 2014.

ÁVILA, Maria Betânia. Liberdade e legalidade: uma relação dialética (Prefácio). In: ÁVILA, Maria Betânia; PORTELLA, Ana Paula; FERREIRA, Verônica (org.). Novas legalidades e democratização da vida social: família, sexualidade e aborto. Rio de Janeiro: Garamond, 2005. p. 17-27.

BATISTA, Carla Gisele; JÁCOME, Márcia Laranjeira. Conservadorismo no Brasil: modos de atuação e estratégias ofensivas aos direitos sexuais e direitos reprodutivos. In: OROZCO, Yury Puello (org.). A presença de mulheres nos Espaços de Poder e Decisão. Cadernos Católicas. São Paulo: Católicas Pelo Direito de Decidir, 2014. p.93102.

CARNAC, Romain. L'Église catholique contre "la théorie du genre": construction d'um objet polemique dans le débat public français contemporain. Synergies, Italie, $\mathrm{n}^{0} 10$, 2014. p.125-143.

CARNAC, Romain. Le gender, ennemi imaginaire des catholiques?, Groupe Societés, Religions, Laïcites, Imaginaires, Paris, 17 fév. 2012. Disponível em:<http://www.gsrl.cnrs.fr/sites/gsrl/IMG/pdf/Romain_Carnac_Le_gender_ennemi _imaginaire_des_catholiques__Re_sume_.pdf > Acesso em 03 avr. 2015.

CARVALHO, Marília Pinto. O conceito de gênero a partir dos trabalhos apresentados no Gt 14 da Anped (1999-2009). Revista Brasileira de Educação (Impresso), Rio de Janeiro, v. 16, n. 46, p. 99-117, 2011.

CLAM. Por que o gênero assusta tanto? Notícias CLAM. Rio de Janeiro. Disponível em: < http://www.clam.org.br/noticias-clam/conteudo.asp?cod=11528 >. Acesso em 07 jun. 2014

CONFERÊNCIA EPISCOPAL PERUANA. A ideologia do gênero: seus perigos e alcances. Lima, Peru, o9 de junho de 2008. Disponível em: <http://www.veritatis.com.br/doutrina/documentos-da-igreja/6616-a-ideologia-dogenero-seus-perigos-e-alcances $>$ Acesso em: 10 jul. 2014.

CONFERENCIA EPISCOPAL PORTUGUESA. Carta Pastoral da Conferência Episcopal Portuguesa. A propósito da ideologia de gênero. Site Apostolado da Oração. Fátima, Portugal, 14 de novembro de 2013. Disponível em: <http://www.apostoladodaoracao.pt/conferencia-episcopal-aprova-carta-pastoral-sobreideologia-do-genero/ > . Acesso em: 05 maio 2014. 
CONSELHO PONTIFÍCIO PARA A FAMÍLIA. Família, Matrimônio e "Uniões de Fato". 26 de julho de 2000. Disponível em:

<http://www.vatican.va/roman_curia/pontifical_councils/family/documents/rc_pc_fam ily_doc_20001109_de-facto-unions_po.html>. Acesso em: 05 ago. 2014.

FAVIER, Anthony. La réception catholique des études de genre. Le genre, approches dépassionnées d'um débat, Hal archives-ouvertes. Sep 2012, Lille, France. Disponível em : < https://halshs.archives-ouvertes.fr/halshs-00765786>. Acesso em 05 ago. 2014.

FELIPE, Jane. Gênero, Sexualidade e a produção de pesquisas no campo da Educação: Possibilidades, Limites e a formulação de Políticas Públicas. Pro-Posições, Campinas, v. 18, n. 2 (53), p.77-87, maio/ago. 2007.

HERVIEU-LÉGER, Daniéle. Vieux interdits, noveaux absolus : le cas de l'approche catholique de la nature. In : CHAMPION, Françoise ;NIZARD, Sophie ; ZAWADZKI, Paul (dirs.). Le sacré hor religions. Paris : L’Harmattan, 2007. p. 241-253.

HERVIEU-LÉGER, Daniéle. Catholicisme, la fin d'un monde. Paris: Bayard, 2003.

LOURO, Guacira Lopes. Um Corpo Estranho - ensaios sobre sexualidade e teoria queer. Belo Horizonte: Autentica, 2004.

LOURO, Guacira Lopes. Gênero, Sexualidade e Educação: uma perspectiva posestruturalista. Petropolis: Vozes, 2001.

LOURO, Guacira Lopes. Teoria Queer - uma política pós-identitária para a educação. Estudos Feministas, Florianópolis, v.9, n. 2, 2001.

LUNA, Naara. Aborto e células-tronco embrionárias na Campanha da Fraternidade. Ciência e Ética no ensino da Igreja. Revista Brasileira de Ciências Sociais, v.25, n.74, p.91-105, out 2010.

LUNA, Naara.As novas tecnologias reprodutivas e o estatuto do embrião: um discurso do Magistério da Igreja Católica sobre a Natureza. Revista Gênero, v. 3, n. 1, p. 83-100. 2/2002.

PERROT, Michelle. Église, sexe et genre : la part maudite. In : MAÎTRE, Jacques; MICHELAT, Guy (orgs.). Religion et sexualité. Paris: L’Harmattan, 2002. p. 193-199

POULAT, Émile. Notre laïcité publique. La France est une République laïque. Paris: Berg International Éditeurs, 2003.

ROSADO-NUNES, Maria José F. De mulheres, sexo e igreja: Uma pesquisa e muitas interrogações. In: COSTA, Albertina de Oliveira; AMADO, Tina (org.). Alternativas Escassas. Saúde, Sexualidade e Reprodução na América Latina. São Paulo/ Rio de Janeiro: Fundação Carlos Chagas / Editora 34, 1994, p.175-203. 
SBARDELOTTO, Moisés. Comunicar o Evangelho da família hoje, como? Revista da Família Cristã: São Paulo, ano 80, n. 944, p. 60-61, ago. 2014.

SER-TÃO: Núcleo de estudos e pesquisas em gênero e sexualidade - UFG. Nota de Repúdio - Retrocessos Na Construção Do Plano Nacional De Educação (PNE). Goiânia Disponível em: <http://www.sertao.ufg.br/pages/69032-nota-de-repudio-retrocessos-naconstrucao-do-plano-nacional-de-educacao-pne>. Acesso em: o5 jun. 2014.

\section{SÍNODO DOS BISPOS. Os desafios pastorais da Família no Contexto da}

Evangelização: Instrumentum Laboris, São Paulo: Paulinas, 2014.

SENKEVICS, Adriano. PNE e a "ideologia de gênero". Ensaios de Gênero. Disponível em: < http://ensaiosdegenero.wordpress.com/2014/o4/12/pne-e-a-ideologia-de-genero/ $>$ Acesso em 20 jun. 2014.

SORJ, Bila. O feminino como metáfora da natureza. Revista Estudos Feministas, v. o, n. o, p 143-15O. Rio de Janeiro: CIEC, Escola de Comunicação - UFRJ. 1992.

SOUZA, Vanderlúcio. Dom Orani alerta sobre perigo da ideologia de gênero no PNE. O Povo Online. Fortaleza. Disponível em:< http://blog.opovo.com.br/ancoradouro/domorani-lanca-nota-alertando-sobre-perigo-da-ideologia-genero-pne> Acesso em: 27 mar. 2014.

TEMPESTA, D. Orani João. Reflexões sobre a "ideologia de gênero". CNBB. Brasília. 28.mar.2014. Disponível em: < http://www.cnbb.org.br/outros/dom-orani-joaotempesta/13907-reflexoes-sobre-a-ideologia-de-genero >. Acesso em: 10 jul. 2014.

VAGGIONE, Juan Marco; MUJICA, Jaris. A modo de introducción: algunos puntos de discusión en torno al activismo (religioso) conservador en América Latina. In: VAGGIONE, Juan Marco; MUJICA, Jaris (comp.). Conservadurismos, Religión y Política: Perspectivas de Investigación en América Latina. Buenos Aires: Ferreyra Editor,2013. p. 17-40.

VARIKAS, Éleni. Droit naturel, nature féminine et égalité des sexes. L Homme et la société, Paris, n.85-86, p.110-111, 1987.

WYLLYS, Jean. Igualdade racial, regional, de gênero e de orientação sexual nas escolas: "o ataque aos princípios norteadores da família”. IG Gay. Brasil, 10 abr. 2014. Disponível em: < http://jeanwyllys.ig.com.br/index.php/2014/o4/10/igualdade-racial-regional-degenero-e-de-orientacao-sexual-nas-escolas-o-ataque-aos-principios-norteadores-dafamilia > Acesso em 27 mai. 2014. 